\title{
CONVERGENT STRABISMUS, MACULAR FOCI AND TOXOPLASMOSIS IN MONOZYGOTIC TWINS* +
}

\author{
BY \\ K. O. Granström and J. Henning Magnusson \\ Stockholm
}

IN an earlier paper, one of us (Granström) described a number of cases of convergent strabismus in monozygotic twins; both " concordance", and " discordance", occurred. Concordance suggests a hereditary genesis, but the latter does not exclude discordance (i.e., genotypical asymmetry according to Dahlberg's theory). A monozygotic pair of twins will be described, in whom, despite pronounced concordance, an exogenous cause of the strabismus must be assumed.

As a rule, no retinal changes are present with strabismus but in exceptional cases an old focus is found in the macula of the squinting eye. This was the case in 10 instances in a series of 1,000 patients with strabismus. In a recently published paper we gave a detailed account of these 10 cases with special reference to the possible occurrence of toxoplasmosis. In six of the cases this disease could be assumed to be the probable cause of the choroid foci in the macula. In this connection the following pair of twins appears to be of interest.

The two boys were monozygotic twins, born on June 6, 1946, three weeks before term. Twin 1 weighed $2630 \mathrm{~g}$. at birth and twin 2, $2800 \mathrm{~g}$. The father was then 40 years old and the mother 35 . Both parents were healthy and domiciled in Stockholm. They had two healthy children, a boy aged five and a girl aged seven, neither of whom showed pathological eye symptoms. The mother had had no abortions.

During the pregnancy in question the mother suffered from slight anaemia but felt well and showed no signs or symptoms of infection. She was under the supervision of an obstetrician the whole time. The pregnancy and labour were normal. The placenta was typical for monozygotic twins with a common chorion and wide anastomoses between both vascularized areas.

The children were in good condition at birth and were sent home from hospital on the 11th day. They' then received breast milk only. They continued to be breast-fed until they were approximately four months old. They then had allaitement mixte until they were seven months old and thereafter a normal mixed diet. Both children developed satisfactorily and were very alike. The first tooth appeared in both instances at the age of six months, they could walk without support at 14 months, said a few words slightly before the age of one and talked perfectly distinctly at the age of two.

They contracted whooping cough at the age of two months. Twin 1 had it very severely and twin 2 mildly. At the age of one they were both operated on for inguinal hernia on the left side. Both had a fairly mild attack of measles at the age of 18 months. During the winter of 1948-1949, they had repeated respiratory

- Received for publication July 15, 1949.

+From the Ophthalmological Department of Södersjukhuset (Head: Dr. K. O. Granström, M.D.) and the Sachs' Hospital for Children (Head: Dr. J. Henning Magnusson, M.D.), Stockholm. 
tract infections which were complicated in twin 1 by otitis whereas twin 2 only showed slight symptoms on each occasion.

Twin 1 began to squint between the age of six and eight months. The squint became more pronounced during the following few months, but has remained constant since then. The parents noticed intermittent squinting in twin 2 from the age of one. In January, 1949, both children were examined at the Ophthalmological Department of Södersjukhuset and were then sent to the Sachs' Hospital for Children for further examination. Since the results of the cutaneous tests with toxoplasma antigen were positive, both children were admitted to this hospital in April, 1949, for clinical investigation. This revealed the following main points.

The children were very alike both as regards general appearance and character. They were of the same height and the colour and texture of their hair were very similar. The ears, nose, lips, eyebrows and the external parts of the eyes were very alike. Both were in good general condition and well developed physically. Intelligence tests according to the Terman-Merrill method resulted in an I.Q. of 91 in both cases. Both children had a systolic murmur, maximal between the 2nd and 3rd intercostal space near the sternum. Electro-cardiography and $x$-ray examination of the heart nevertheless revealed normal and very similar conditions in both children. 'There were no other demonstrable signs of disease except in the eyes. The haematological and serological tests showed the following: Twin 1 had a haemoglobin count of 85 per cent., Twin 286 per cent. Both belonged to the blood group combination $\mathrm{B}$ MN Rh $(+)$.

The results of the ophthalmological examination were the following:

Twin 1: Testing of the vision was not possible. There was a distinct convergent strabismus of the right eye. He could focus with both eyes, but somewhat uncertainly with the right. The movements of the eyes and the pupils were normal and the media clear. Fundi: In the right macula there was a round, old chorioretinal focus, somewhat larger than the papilla, partly pigmented but mainly atrophic. As far as it was possible to ascertain, the fundi were otherwise normal. The left macula was normal. The discs were normal.

Twin 2: The findings were identical with those in his twin brother. The strabismus and choroid focus were, however, on the left side. The foci were extremely alike in both cases.

As shown in the Table the dye test according to Sabin and Feldman was positive in both children and their parents but negative in both the older siblings. Radiological examination of the head revealed no calcifications.

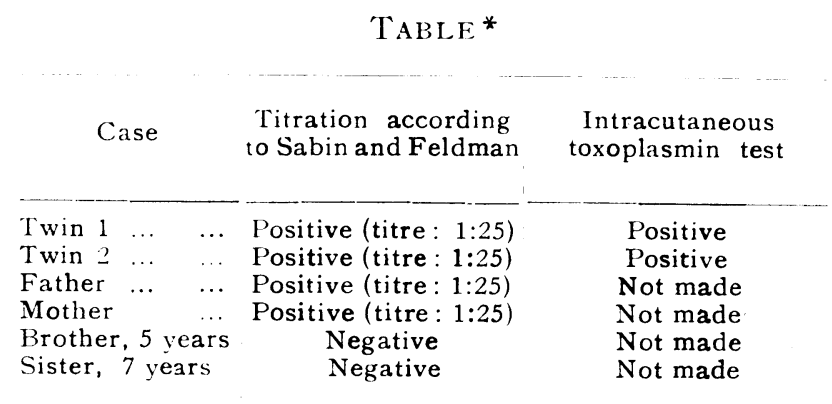
We wish to thank Prof. S. Gard who performed the titrations and supplied us
with toxoplasma antigen.

We are thus dealing with a definitely monozygotic pair of twins, both with convergent strabismus in one eye (inverse asymmetry). In the macula of this eye there was a healed chorioretinal focus of atypical but almost identical appearance in both children. The positive serological reaction for toxoplasmosis in both children 
and in the mother affords very strong evidence in favour of this disease as the cause of the macular foci and thereby-through impaired vision-indirectly of the strabismus. Despite the pronounced concordance the strabismus must in these patients be considered as exogenously conditioned.

We were able to find two reports in the literature of monozygotic twins suffering from toxoplasmosis and lesions of the eyes. One of Zuelzer's patients died at the age of one month. Post-mortem examination revealed iritis, chorioretinitis in the macula and the intraocular presence of parasites. The other twin was under observation between the age of one and seven months and suffered from chorioretinitis and microphthalmos. In Abbott and Camp's cases, both twins exhibited bilateral widespread chorioretinitis associated with retinal angiomatosis.

\title{
SUMMARY
}

The patients are two definitely monozygotic twins. Both exhibited convergent strabismus as well as a healed chorioretinal focus in the macula of the affected eye. Serological tests for toxoplasmosis were positive in both twins and in both their parents. Despite the pronounced concordance the strabismus must in these patients be considered as exogenously conditioned.

\section{REFERENCES}

Аввотt, K. H. and Cam P, J. D. (1947).-Bull. Los Angeles Neurol. Soc., 12, 38. Granström, K. O. (1936).-Acta Ophthal., 14, 72.

Granström, K. O. and Magnusson, J: H. (1948).-Acta Ophthal., 26, 223.

- (1949).-Arch. frangaises de Pédiatrie.

HERTH, P. and ZUELZER, W. W. (1945).-Arch. Ophthal., 33, 184.

Zuelzer, W. W. (1944).-Arch. Path., 38, 1.

\section{THE PATTERN OF THE CORNEAL INNERVATION IN RABBITS*}

\author{
BY \\ F. C. RODGER \\ Department of Physiology. \\ University of Durham
}

As a necessary preliminary to investigations into the nature of the corneal permeability a histological study of the corneal innervation was undertaken.

Two techniques were finally chosen as being the most suitable, methylene blue and gold chloride. In general one might say that

\footnotetext{
- Received for publication August 15, 1949.

Demonstration presented to the Physiological Society at Oxford, July, 1949.
} 